\title{
Modos de vestir e identidades de género: reflexiones sobre las marcas culturales en el cuerpo
}

\section{Laura Zambrini ${ }^{1}$}

\section{Introducción}

El presente artículo es parte del marco teórico desarrollado en mi tesis de doctorado, en la cuál se indaga la relación entre las identidades de género, los cuerpos y las vestimentas en el contexto de la cultura visual. Específicamente, en la tesis analizo las formas de representación del colectivo travesti en la prensa gráfica argentina contemporánea, estableciendo como principales ejes de indagación las narrativas sobre el cuerpo y la indumentaria. Sin embargo, aquí en esta oportunidad presento un abordaje sociológico acerca de ciertos aspectos teóricos referidos al papel histórico que ha tenido, y tiene aún, la indumentaria en el proceso de naturalización de las identidades de género binarias (femeninas o masculinas).

Los objetivos generales propuestos para este trabajo han sido por un lado, historizar la heteronormatividad, y las identidades de género binarias en tanto construcciones sociales (y no naturales). Y por otro, estudiar la complementariedad que ha tenido la indumentaria en el fortalecimiento de dicha matriz heteronormativa. Es decir, echar luz respecto a cómo la indumentaria ha acompañado este proceso haciendo legibles socialmente los cuerpos según las apariencias.

En la primera parte del trabajo, realizo un breve recorrido por la historia de la moda desde una genealogía de las prácticas del vestir para analizar los modos en que los cuerpos adquieren significado a partir de los discursos sociales. A modo introductorio, se recorren los inicios de la moda y sus distintas etapas en base, entre otros autores y autoras, a los trabajos de Norbert Elías (1977), quien plantea la idea de civilización en las sociedades 
occidentales atravesadas por la herencia de la sociedad cortesana. Una vez explicada la etapa aristocrática de la moda, su desarrollo y crisis, se analiza la etapa burguesa. Es decir, la etapa propia del capitalismo donde emerge la distinción social como relación social privilegiada, tal como lo propone Pierre Bourdieu (1998).

En la segunda instancia del trabajo, el recorrido histórico previo permite comprender lo binario como ordenamiento de lo social para pensar el género. Para ello se hace referencia a los trabajos de Michel Foucault (2003 [1977] y 1989) en torno las sociedades disciplinarias y la historia de la sexualidad. Si bien Foucault, jamás habló sobre el género y la vestimenta, sus planteos sobre los cuerpos disciplinados también se pueden relacionar con la historia del vestir en occidente. Numerosos trabajos de autoras feministas postestructuralistas, como por ejemplo, aquellos subscriptos en la línea teórica propuesta por Judith Butler (1999), han incorporado la noción de poder esbozada por Foucault para explicar al cuerpo generizado como una construcción de la modernidad y del pensamiento binario.

Luego, desde la perspectiva teórica enunciada, analizo la importancia del siglo XIX en dicho proceso porque para los historiadores del traje, fue a partir del siglo XIX que la vestimenta incrementó la división de los imaginarios de lo femenino y lo masculino. En dicho siglo, occidente recreó a través de la moda dos patrones excluyentes en los modos de vestir, uno para hombres, y otro para mujeres, y ambos debían connotar valores opuestos (no sólo de valores de distinción social sino también de género). Esta etapa es denominada "La Gran Renuncia del siglo XIX" (producto de la modificación de las relaciones sociales en el marco de la Revolución Industrial y consolidación del Capitalismo). A partir de la figura de la Gran Renuncia en el siglo XIX, puede verse con mayor rigor la separación genérica en los modos de vestir, dejando los elementos decorativos relegados a lo femenino. La indumentaria femenina dio lugar al uso de accesorios, recreando una estética femenina asociada al adorno y a lo decorativo como rasgo identitario que a primera vista se diferenciaba de lo masculino. Otro aspecto importante a tener en cuenta, es la supuesta división de los mundos privados y públicos. Lo femenino fue asociado a los ámbitos privados -reproductivosdecorativos, lo cuál también comenzó a tener un correlato en los 
modos de vestir. En cambio, lo masculino fue relacionado con el trabajo y lo público.

Seguidamente, se enuncia la llegada de la fotografía y de las revistas al sistema de la moda. Y se plantea la importancia que ha tenido en el desarrollo de la cultura visual como forma de conocimiento privilegiado en occidente, y en el desarrollo de una sociedad basada en el consumo masivo a modo de lazo social que encontrará su esplendor en el siglo XX. La noción de visualidad esbozada refiere a los dispositivos y operaciones ideológicas que hacen legibles, y por ende, "normales" a los cuerpos en la cultura.

Y por último, en la tercer parte del trabajo, analizo el vestir como técnica corporal desde una perspectiva de género. Para pensar el cuerpo han sido utilizadas las nociones de Marcel Mauss (1950) respecto a las técnicas corporales. En la lógica heteronormativa y binaria, las técnicas corporales femeninas por definición se diferencian de las masculinas, y han operado históricamente en consonancia con los modos de vestir.

En este sentido, el planteo general del artículo nos remite a la relación entre el cuerpo y el vestir como una práctica corporal contextuada. Esta práctica alude a las formas concretas en que se presentan los cuerpos de acuerdo a las construcciones culturales que producen a las identidades como socialmente inteligibles. Dicha clasificación estética del mundo no es armónica, por el contrario, supone una permanente tensión y negociación respecto a cuáles identidades se reconocen como tales, y cuáles se transforman en diferencias $\mathrm{u}$ otredades.

\section{Breve recorrido por los orígenes de la moda}

El devenir de la moda invita a reflexionar acerca del florecimiento de la sociedad moderna en Europa, y los diversos cambios socio-históricos, políticos y culturales que han transformado la vida social a partir de la consolidación de los valores de la modernidad. La cultura occidental ha sufrido distintas mudanzas a lo largo de su compleja historia y, en cada una de ellas, las prácticas del vestir han tenido funciones sociales acordes al contexto. La indumentaria ha sido estudiada a partir de las diferentes funciones que desempeñó de acuerdo a la época. Desde un plano 
pragmático, la vestimenta suele ser vista a partir de su ejercicio de protección del cuerpo frente a las condiciones climáticas. Y desde un plano de orden simbólico, puede ser interpretada como la expresión de valores y marcas culturales de tipo religioso, político, jerárquicos y distintivos.

Pensar la moda supone que la misma no opera como un fenómeno aislado e independiente de la sociedad en la que se ha gestado y de los cambios socio-culturales producidos. Por el contrario, existe una tendencia hacia la reciprocidad entre las formas de vestir de las personas, los valores culturales y el mundo social. Cada época histórica tendrá como correlato determinados patrones estéticos y usos de indumentarias que expresan una cosmovisión ligada a un tipo de orden social. Es decir, la estética de una época se devela al poner en diálogo los distintos modos de vestir y la vida social (Laver, 1989).

A diferencia de la función social que las prácticas del vestir habían tenido en la denominada Etapa Aristocrática (Riviere, 1977), la moda surgió en la sociedad moderna y capitalista denotando las necesidades de cambio constante como rasgo cultural principal.

Excede los objetivos del presente trabajo el desarrollo -con mayor detenimiento- de la intrincada historia del traje y la moda, y sus distintas etapas; pero destacamos que la transición de los valores de la aristocracia ligados a las Cortes Medievales y al Feudalismo en Europa, se contraponían a los valores de la naciente burguesía. Dicha puja tuvo como escenario privilegiado al campo político, que a su vez, puede rastrearse en el campo del arte y de la creación de indumentaria. A lo largo del trabajo, nos referiremos a la moda "en sentido moderno" pues previamente no podría ser catalogada como tal. Asimismo, se establece que las concepciones acerca de la elegancia y el buen gusto en el vestir como atributos deseables y estéticos de las personas, están relacionadas con el proceso sociológico que instaló la idea de civilización en occidente, herencia de la sociedad cortesana (Elías, 1977). Estos patrones sellaron los antecedentes y los parámetros estilísticos para el posterior desarrollo de la Alta costura.

Elías sugiere que la Edad Media funcionó como una etapa de transición pues ha sido en dicho momento histórico donde surgieron los primeros manuales de etiqueta y de comportamiento 
social. A grandes rasgos, podemos afirmar que en las etapas anteriores a la moda burguesa, predominaban en Europa las elites aristocráticas que controlaban formalmente el privilegio del vestir. Mediante el dictado de las Leyes Suntuarias se prohibía el uso de determinadas ropas, telas y / o colores a todos aquellos que no pertenecieran a las cortes, a la nobleza y/o al clero, por ejemplo. Fueron un conjunto de disposiciones legales cuyo objetivo era regular la diferenciación social basada en la indumentaria y el lujo. De este modo, se impedía formalmente que los individuos no pertenecientes a la aristocracia pudieran emular una mejor pertenencia social mediante la vestimenta. Dichas leyes dictaminaban qué tipo de ropa y colores podían ser utilizados de acuerdo a la jerarquía social, permitiendo por lo tanto identificar y separar visualmente los rangos y las actividades sociales.

Los historiadores de la moda destacan la importancia de las Leyes Suntuarias en la historia social entendidas éstas como materiales concretos de comunicación para la comprensión de la dimensión simbólica de las prácticas del vestir con fines identitarios. El período de normatividad más significativo fue la baja Edad Media y los comienzos de la Edad Moderna, momento en que comienza poco a poco la moda (Guglielmi, 2004). Este sistema del vestir respondía a sociedades cuyas estructuras internas se caracterizaban por la fijeza de los roles sociales. Por ende, la indumentaria refería -a simple vista- las identidades de los sujetos de acuerdo a sus actividades y posiciones en la escala social. Existían trajes que comunicaban la función social en consonancia con la actividad desempeñada: atuendos de guerreros, de campesinos, de siervos, trajes para la realeza y otros para los cortesanos, a modo ilustrativo. Eran sociedades estratificadas a partir de estamentos rígidos siendo imposible el traspaso de uno hacia otro. Las posesiones de las tierras y de los títulos de nobleza -heredados mediante lazos sanguíneos- funcionaban como los principales atributos para gozar un lugar social acomodado.

El ascenso de la alta burguesía mercantil como grupo social dominante posibilitó que estas características fuesen modificándose paulatinamente. Los principales acontecimientos que utilizamos como referentes históricos para enmarcar dichos procesos son: la Revolución Francesa, la Revolución Industrial y la posterior consolidación del sistema capitalista. La indumentaria en el siglo XVIII estuvo influenciada por los estilos barroco, rococó 
y neoclásico. Luego, los trajes comenzaron a confeccionarse con menos recarga dando paso a diseños más simples. El acceso por parte de la burguesía al dinero pero no al linaje, fue determinante en la disputa por el prestigio social y los privilegios en el vestir. El advenimiento del capitalismo hizo que las Leyes Suntuarias perdieran sentido dando paso a la lógica de la distinción social (Bourdieu, 1998).

La emergente sociedad de clases impuso un sistema del vestir que lograba expresar los potenciales cambios internos en la estructura social y las nuevas identidades colectivas. En esta etapa surgió la moda propiamente dicha, es decir, con innovaciones permanentes de estilos estéticos y cambios relativos en las jerarquías sociales. Al modificarse el entramado social a causa del liderazgo de los valores burgueses, entre otros factores, posibilitó que tanto el dinero como los ideales de libertad e igualdad adquirieran un valor categórico. Este proceso estuvo acompañado por las mutaciones en el sistema productivo y en las tecnologías, transformando al trabajo de la industria fabril en el principal organizador de lo social. El crecimiento de las ciudades y la consecuente concentración de las poblaciones en las urbes, la necesidad de ampliar los mercados adónde vender lo producido, posibilitado a su vez por el intercambio de materias primas entre las colonias -especialmente en el rubro textil- fueron los impulsos necesarios para el desarrollo de la industria de la moda.

Desde esta perspectiva, se afirma que el cambio social y la moda se unieron de manera significativa. En este momento histórico nacieron los recambios de las ropas por temporadas (Otoño, Invierno, Primavera, Verano). En épocas anteriores, a excepción de los estratos acomodados, las personas solían tener uno o dos trajes durante toda su vida. La moda burguesa rompió con estos hábitos e introdujo el gusto por el cambio constante en el vestir. Los ciclos de la moda se adaptaron a los ritmos industriales, y encontraron sociedades que absorbieron positivamente la democratización en el vestir y el consumo. Se considera que los sucesos más relevantes que impulsaron el nacimiento de la moda fueron: el desarrollo de la sociedad cortesana y el Renacimiento, la expansión del comercio a partir de las Cruzadas, el afianzamiento de la burguesía como la clase que concentraba las riquezas y la vida urbana e industrial, entre otros. A diferencia de la etapa anterior, donde el vestir tenía un fin clasificatorio, la 
Era Moderna sentó las bases para el afianzamiento de un sistema del vestir basado en el cambio continuo ya que la moda necesitó una sociedad que tenga relativa movilidad interna para su pleno desarrollo. Este es uno de los argumentos, por las cuáles se interpreta que la moda no haya sido impulsada en el orden feudal (Entwistle, 2002).

En el año 1860, el diseñador Charles Worth creó la primera firma de Alta costura en Francia, marcando durante mucho tiempo los principales parámetros de la elegancia y el buen vestir difundidos a través de los catálogos de moda con fines elitistas y distintivos. Por su parte, la creación de la máquina de coser habilitó una confección seriada que forjó prendas de baja calidad y bajo precio/costo dirigida a la distribución masiva en las grandes tiendas. De este modo, se consolidó un sistema de la moda bipartito, es decir, compuesto por dos elementos: la Alta costura y la confección seriada (Saulquin, 1990). Según Gilles Lipovestky (1994), la democratización de la moda llegó por causa de la burguesía puesto que la mayoría de las clases populares accedió al consumo de la misma. No obstante, los privilegios del vestir persistieron en manos de unos pocos liderados por la alta burguesía. Es por ello que Margarita Riviere (1977) sostiene que, en un principio pareció ser efectiva la democratización vestimentaria. Pero más tarde lo fue sólo a modo parcial porque mediante la Alta costura, la elite burguesa conservó el privilegio del vestir al igual que la aristocracia lo hizo en épocas anteriores amparada en las Leyes Suntuarias. A partir del siglo XIX, comenzaron a ser presentadas las colecciones de moda, indicando las prendas y estilos que deberían ser usados en la próxima estación o temporada. Aquí surgió la figura de los estilistas como aquellos que proponían y dictaminaban a la moda.

La moda fue catalogada por la incipiente Sociología ${ }^{2}$ clásica del siglo XIX, como un fenómeno contradictorio que evidenciaba la lucha social debido a la estratificación de los distintos sectores sociales. Por un lado, se destacaba la presencia de una elite portadora de los bienes de distinción y, por otro, una inmensa mayoría que intentaba adoptar y / o imitar dichos símbolos distintivos. Las luchas de aspiraciones se consolidaban cuando la elite trataba -al sentirse amenazada- de alejarse lo más posible de la masa creando nuevos símbolos de distinción social (Martínez Barreiro, 1998). Autores como Herbert Spencer (1947) y George 
Simmel (1938), postularon que la moda estaba atravesada por el fenómeno de la imitación social siendo las clases más pudientes las que intentaban separarse a partir de las apariencias (mediante la ropa, especialmente) de las clases más bajas. A su vez, éstos últimos mediante la imitación de los sectores más acomodados pretendían emular una mejor pertenencia social. Para Simmel (1938), los juegos de las imitaciones y/o distinciones resultaron funcionales para el desarrollo del sistema capitalista porque favorecieron el consumo. Por esta razón, el autor argumentó que la moda tuvo la función social simultánea de "unir y diferenciar" a una sociedad que se encontraba dividida en diversas clases sociales. La moda cohesionaba a los distintos grupos a la vez que los diferenciaba entre sí. Thortein Veblen (1974), destacó que la indumentaria funcionó como un símbolo de ocio porque una "apariencia elegante" brindaba información acerca del lugar que el sujeto ocupaba en la estructura productiva. El autor mediante la Teoría de la clase ociosa destacó que un individuo al invertir su dinero en el consumo de la moda/indumentaria, mostraba a los demás -en una primera instancia-su capacidad adquisitiva mediante un derroche ostensible.

Tal como se ha dicho, Lipovetky (1994) y Susana Saulquin (1990) describen que en la denominada etapa burguesa de la moda (Riviere, 1977) se conformó un sistema del vestir que los autores caracterizan como bipolar cuya función era básicamente manifestar y salvaguardar la distinción social. El sistema de la moda brindó identidades a los sujetos y los mimetizó en lo masivo sentando las bases culturales para el pleno desarrollo durante el siglo XX de una cultura de masas (Morin, 1962). De acuerdo a Lipovestky, aposteriori la juventud se gestó como una condición valorizada, producto de una sociedad que se empezaba a concentrar en el tiempo presente, en la imagen y en el consumo como lazo social.

\section{Lo binario como ordenamiento social}

A partir del siglo XVIII la moda se consolidaba en Europa, y estaba dirigida por los mandatos autoritarios y exclusivos de los diseños de la Alta costura. Como hemos visto, el funcionamiento del sistema de la moda bipolar funcionó también en el siglo XIX, 
y encontró su esplendor a mediados del siglo XX con la cultura de masas. Esto respondía a una sociedad cuyas identidades eran relativamente estables pues los Estados nacionales y el trabajo industrial/fabril contenían y regulaban la vida social mediante políticas que tendían a la integración social (Zambrini, 2009).

Foucault (1989, 2003 [1977]) señaló que en esta etapa, los dispositivos disciplinarios fueron constitutivos de la organización social capitalista. En las sociedades disciplinarias -nacidas en el siglo XVIII y XIX, y encontrando su esplendor en el siglo $\mathrm{XX}$ - los sujetos eran regulados mediante dispositivos de encierro que funcionaban como instituciones ordenadoras de lo social. Mediante la metáfora del Panóptico, el autor sugirió que los mecanismos de dominación eran asociados a la idea de vigilancia, considerando que la sociedad moderna se caracterizaba por lo carcelario, es decir, una sociedad que vigila y castiga a través de sus instituciones. Esto supone operaciones de poder que moldean los cuerpos a través de discursos que se constituyen en regímenes de verdad, y establecen las condiciones de posibilidad del pensar y del hablar, e inclusive engendran las resistencias al mismo. El autor establece una noción histórica sobre la idea de normalidad de los sujetos y sus cuerpos, que actúan en formas de tecnologías del yo (Foucault, 1990). Si bien Foucault jamás relacionó su teoría con la moda y las prácticas del vestir, algunas perspectivas de análisis sostienen que sus planteos sobre el disciplinamiento de los cuerpos también se pueden rastrear y enlazar con la historia de la moda (Turner, 1989; Enwistle, 2002). En el siglo XIX, la figura del corsé femenino ilustra una forma de disciplina y opresión sobre los cuerpos de las mujeres porque el uso de dicha prenda era asociado a cuestiones morales. Las nociones de Foucault en torno al poder, pueden ser relacionadas con las prácticas del vestir para comprender los modos en que los cuerpos adquieren significado a partir de los discursos sociales.

La perspectiva de género no está presente en la obra de Foucault, no obstante, algunos trabajos feministas posteriores como los realizados por Judith Butler (1999) por ejemplo, han incorporado la noción del poder foucaultiano para explicar al cuerpo generizado a partir del esquema binario identitario de lo femenino y lo masculino como un constructo de los discursos de la modernidad (Zambrini y Iadevito, 2009). En este marco, se considera que la indumentaria cumple un papel esencial puesto 
que marca y refuerza las fronteras de las identidades de género binarias e inscribe significados culturales sobre los cuerpos. De este modo, se enriquece el análisis a partir de la incorporación de una genealogía de las prácticas del vestir.

Para los historiadores de la moda y el traje, es a partir de la mitad del siglo XIX que la vestimenta incrementó la división entre los mundos e imaginarios femeninos y masculinos. Occidente, en ese momento histórico, recreó a través de la moda dos patrones en las formas de vestir excluyentes entre sí: uno para los hombres y otro para las mujeres. Ambos patrones simbolizaban valores opuestos, por un lado la ropa femenina debía denotar el sentido de la seducción de las mujeres; y por otro lado, dicho sentido tenía que estar ausente en los atuendos masculinos (Dutra é Mello, 2007). Los trajes femeninos se tornaron más complejos en cuanto a sus confecciones, las telas y los bordados utilizados. En cambio, los trajes masculinos sufrieron el proceso inverso debido a la simplificación de los modelos que los despojó de casi todo elemento decorativo.

Esta etapa es denominada la "Gran Renuncia del siglo XIX", en la que los valores del puritanismo de la etapa victoriana $y$ los cambios producidos por la Revolución industrial transformaron los comportamientos sociales y las relaciones cotidianas. Desde el Renacimiento hasta mediados del siglo XIX, la historia de la moda evidencia que tantos hombres como mujeres solían vestirse de manera extravagante y lúdica. Nobles y burgueses compitieron por el poder a través de las ropas hasta alrededor de la década de 1830, luego los valores puritanos y los cambios causados por la Revolución Industrial reestructuraron los comportamientos sociales, y también las lógicas del vestir (Dutrá e Mello, 2007).

Los modos de vestir masculinos fueron transformados en Europa por influencia de los ideales franceses de fraternidad y por la figura estética del dandy inglés como modelo privilegiado. El traje masculino tendía a la uniformidad y a la sobriedad -a diferencia de los usados en la etapa aristocrática en las cortes- $y$, les permitía a los hombres connotar rectitud, elegancia, formalismo, limpieza y distinción social, en oposición a la estética de la belleza y la sensualidad que eran considerados atributos exclusivos de lo femenino. 
La figura de la Gran Renuncia nos invita a reflexionar acerca de las implicancias simbólicas en torno al refuerzo de una conformación binaria y jerárquica de los géneros que tuvo, por un lado la separación genérica de los modos de vestir, y por otro que los elementos decorativos dejaran de formar parte de los atuendos masculinos, y quedaran relegados a lo femenino. El vestuario de los hombres perdió su función ornamental, y privilegió la uniformidad como atributo de decoro y buen vestir, pero especialmente como atributo de masculinidad. De este modo, además de las marcas de la distinción social y del acceso a los ámbitos de poder ligados al orden público y económico. La indumentaria masculina, a su vez, pasó a simbolizar la naturalización de la identidad sexual $\mathrm{y} / \mathrm{o}$ de género en oposición a la identidad femenina, $\mathrm{y}$ viceversa ${ }^{3}$.

El traje femenino en el siglo XIX, en cambio tendió a marcar la silueta y las formas de los cuerpos de las mujeres recuperando el uso del corsé, los miriñaques y los grandes escotes. Se utilizaban adornos variados y en cantidad (por ejemplo, plumas, moños, flores), y a la vez, se combinaban con capas superpuestas de distintas telas, tocados que realzaban los peinados, sombreros, zapatos y botas de tacón, etc. La cintura estrecha, el busto abombado tendiendo hacia delante, efectos producidos por el uso del corsé, la falda con cola ajustada a las caderas, que quedaban desplazadas hacia atrás, los cuellos altos y los adornos que al caminar producen efecto de movimiento, originan en los últimos años del siglo XIX la primera manifestación del Modernismo en el vestido (de Sousa Congosto, 2007, 202).

La indumentaria femenina dio lugar al uso de objetos complementarios en las formas de vestir tales como abanicos, guantes, chales, carteras, aros, etc. La combinación de la ropa con los accesorios, recreó un estereotipo de una estética femenina asociada al adorno y a lo decorativo como rasgo identitario que a primera vista se diferenciaba de lo masculino. Por otra parte, las modas femeninas estaban basadas en el uso de prendas que dificultaban los movimientos corporales de las mujeres. Esto consolidaba el imaginario moderno que las alejó de la fase productiva. $Y$ reificaba la supuesta división entre una esfera pública (asociada a lo masculino) de la otra esfera privada, ligada a lo doméstico como ámbito de la femineidad.

La división sutil de los géneros por medio de las apariencias, también impregnó la puja entre las clases sociales pero con 
características diferentes. El consumo de moda quedó asociado a las clases que tenían una mejor pertenencia social debido a la posesión de dinero, y la consecuente posibilidad de plasmar en las prácticas del vestir la distinción social. La redistribución del ingreso, el capital y las condiciones laborales eran discusiones que concernían al orden público y que por lo tanto, dejaban de lado a las mujeres. Las primeras reivindicaciones feministas nacieron peleando contra la configuración del orden patriarcal, y denunciando la construcción de la representación de la mujer en tanto objeto erótico ideal y deseo en pos de la mirada masculina (de Beauvoir, 1999 [1949]). Es decir que, a grandes rasgos, el feminismo surgió cuestionando y buscando una posibilidad de negociación de los espacios de poder que relegaban a las mujeres hacia la domesticidad de manera pasiva, y las reducía a frágiles objetos decorativos, o bien, reproductivos.

A su vez, el siglo XIX, fue una etapa de grandes cambios en la historia de la moda. Los ciclos del sistema de la moda comenzaron a acelerarse, entre otros aspectos, debido a la necesidad de la aristocracia y la burguesía (muchos devenidos en nuevos ricos) de distinguirse de las clases populares. El sector social trabajador accedía al consumo de mayores y mejores prendas puesto que eran menos costosas gracias a la producción seriada industrial. Este incremento en la demanda propició el surgimiento de los grandes almacenes de ropa. Francia seguía siendo el epicentro de la moda femenina, e Inglaterra de la moda masculina. Ambos países marcaron -en este momento- los parámetros estéticos a seguir colectivamente, difundidos en incipientes catálogos de moda que mostraban figurines e ilustraciones de los diseños. Posteriormente, se consolidaron las revistas de modas con diferentes características y objetivos. Por un lado, se encontraban las publicaciones dirigidas a las mujeres como potenciales consumidoras, y por otro, las dedicadas a las personas vinculadas al rubro textil como profesión (sastres, costureras, etc.).

En este período, la indumentaria no sólo se polarizó acorde a las identidades de género y / o sexuales binarias, y la pertenencia social. Además, las formas del vestir de los niños y niñas se separaron por completo de los atuendos usados por las personas en edad adulta (de Sousa Congosto, 2007).

La llegada de la fotografía brindó los canales necesarios para 
el desarrollo paulatino de una sociedad que diversos autores catalogan como la cultura de la imagen (Sabsay, 2009). Hacia finales del siglo XIX algunas revistas de modas incorporaron las producciones fotográficas, las cuáles tuvieron un papel central durante el siglo XX. Desde esta perspectiva, se sostiene que el afianzamiento del sujeto moderno implicó el establecimiento de la vista como el sentido más importante para el acopio de conocimiento y clasificación de las identidades sociales. Conjuntamente, la visualidad ha adquirido en occidente relevancia cultural como forma de comprensión, conocimiento y dominio político del mundo (Penhos, 2005; Arfuch y Devalle, 2009). Por lo tanto, lo visual se relaciona a la vez, con las formas históricas y culturales que determinaron y estructuraron la mirada de la subjetividad moderna en "modos de ver" hegemónicos y normatizadores. Dichos elementos simbólicos se materializan en la producción de normas que han naturalizado las identidades sociales hasta nuestros días. No obstante, son construidas históricamente, y se ejercitan en operaciones ideológicas que comprenden también la corporalidad y las prácticas del vestir como dispositivos que hacen legibles y "normales" los cuerpos en la cultura.

\section{El vestir como técnica corporal: Moda y Género}

La historia del arte ha sugerido que el orden visual (como forma de percepción y cognición) intervino en la manera en que el sujeto de la modernidad ha conocido y representado su propio cuerpo, y el de sus semejantes. La modernidad teñida de los valores racionales, positivistas y binarios implicó el establecimiento de comunidades de sentido (en detrimento de otras) que son compartidas por el colectivo social operando en un proceso naturalizante de prácticas y valores socio-culturales. Dichos valores, participaron en la lucha que implica toda construcción de las identidades y otredades, y por ende también, en la construcción de las identidades generizadas (Arfuch, 2002).

Desde esta perspectiva teórica, se asume que el género es establecido como una tecnología, es decir, un proceso complejo propio de la modernidad que está orientado a la producción de sujetos "normales" a partir de la regulación de la praxis pregonando a la heterosexualidad como la norma principal, y a la 
homosexualidad como un tabú o una desviación ${ }^{4}$ (Becker, 1971).

El género como tecnología también determina los modos de tipificar los cuerpos de las personas y de interpretar lo social (Foucault 1990 y 2003 [1977]). A través de la dimensión corporal se ejerce la regulación y el control social de los sujetos, puesto que es en la operación clasificatoria donde se ejerce la presión de la norma. Esta es una de las principales razones a través de la cuál, la sociología ha interpretado las prácticas del vestir y, en especial a la moda, como hechos sociales que ponen en evidencia la construcción cultural -no solamente- de los usos de la indumentaria sino también de la conformación social de los cuerpos.

Desde esta óptica, el cuerpo occidental es pensado como una construcción simbólica atravesada por la herencia del imaginario dualista (que divide cuerpo - mente/ espíritu) propio de la filosofía cartesiana de la modernidad. La noción del cuerpo moderno está vinculado al llamado proceso de individualización, en ruptura con las concepciones del orden y el cuerpo tradicional que se integraba al entramado social y a la Naturaleza como parte de un todo en armonía (Lebreton, 2002). En contraste, el cuerpo moderno surgió en el Renacimiento, apelando a la noción de un "yo" que se separa de un "otro", y lo convierte en individuo. El cuerpo se transforma en el lugar de la frontera que distingue a cada individuo de sus otros pares, y los rostros operan como la marca principal de la diferencia íntima y subjetiva ${ }^{5}$.

Marcel Mauss (1950) describió al cuerpo como un constructo cultural relativo a cada contexto social específico. De este modo, según el autor, de acuerdo a la sociedad y al momento histórico, se valoran positivamente algunos comportamientos (que comprometen al cuerpo) en desmedro de otros. Mauss analizó las llamadas técnicas corporales como formas de clasificación que involucran también a la dimensión de género y / o sexual en tanto ordenador de los cuerpos y por ende, de la vida social. El aprendizaje de las técnicas corporales de género en la socialización posibilita que los sujetos naturalicen la cultura, y la reproduzcan a través de prácticas en los cuerpos generizados.

Según Elizabeth Badinter (1986), los roles tradicionales de las identidades de género fueron comprendidos, constituidos y organizados binariamente en función de la naturaleza a partir de la diferencia sexual. Esta división, aparentemente natural y neutral, fue el sustento ideológico de la modernidad que 
justificaba la separación de los géneros en el mundo social, y las consecuentes asimetrías en las relaciones de poder. La construcción social de la masculinidad y la feminidad ha supuesto formas corporales distintas y opuestas, así como también, manifestaciones gestuales, el control de las emociones, hábitos, gustos y actitudes diferenciados entre sí. En esta lógica, las técnicas corporales femeninas difieren de las masculinas, y operan en consonancia con la visualización y los usos del vestir. Peter Fry (1982) destaca la importancia del ejercicio de los roles de género en el proceso mismo de la construcción de las identidades. Mientras que la moda quedó históricamente cristalizada como un espacio de desempeño y actuación de los papeles femeninos, los hombres que desplegaran dichos roles serían normatizados desde los patrones indicativos de la desviación de la masculinidad. Erving Goffman (2003 [1963] y 2004 [1959]) describe los mecanismos por los cuáles la sociedad categoriza a sus miembros a partir de ciertos atributos considerados normales. Estos atributos operan en formas de expectativas normativas de las conductas ${ }^{6}$, por lo tanto cuando la presentación de la persona no concuerda con las expectativas sociales, es altamente probable que surja el estigma y la sanción social.

El vestir, para la sociología, es un hecho social que opera con relación a un contexto que le otorga legitimidad (o no) a dicha práctica vestimentaria. Por lo tanto, la relación entre el cuerpo y la indumentaria es caracterizada como una práctica corporal contextuada, que remite a las formas concretas en que se presentan y exhiben los cuerpos de acuerdo a la construcción cultural que produce a las identidades como socialmente inteligibles (Entwistle, 2002). La clasificación estética del mundo supone una permanente tensión y negociación respecto a cuáles identidades son susceptibles de ser visibilizadas legítimamente, y cuáles se transforman en diferencias u otredades. Porque las prácticas del vestir, en tanto discurso estético, hacen referencia a la comunicación y clasificación social de los cuerpos generizados, haciéndose inteligibles en términos identitarios para la mirada de la sociedad (Zambrini, 2008).

En este sentido, resulta fundamental destacar una caracterización antiesencialista de la noción de identidad. La identidad aquí es entendida como un proceso abierto en permanente cons- 
trucción y puja basado en sistemas regulados dotados de significados y representaciones (Arfuch, 2002). Es dicha puja la que conlleva a las distintas posiciones de sujetos en la escena social. En palabras de Stuart Hall, las identidades son asi puntos de acoplamiento temporal a las posiciones de sujeto que las prácticas discursivas vienen a construir para nosotros (Hall, 1996, 19). Ciertamente, se plantea la identidad como un producto de prácticas discursivas que están atravesadas por prácticas culturales más amplias (Foucault [1977], 2003).

De este modo, plantear la identidad y la diferencia/otredad como una relación social o de fuerzas, implica asumir que dicha relación no es armónica, por el contrario, supone jerarquías y disputas; y por lo tanto, nos conduce al planteo de la temática del poder. Pues, en todo acto discursivo de afirmación identitaria y de enunciación de las diferencias, están en juego bienes simbólicos y materiales de los distintos grupos sociales, y por ende, las complejas tramas de poder que atraviesan lo social (Hall, 1996).

Alegar una identidad, y establecer su diferencia, supone una operación de inclusión y exclusión sostenida en la existencia del binomio nosotros/ellos. Es decir, se recrean los procesos de clasificación social y delimitan las distintas fronteras en el plano de la identidad que hacen a la dinámica de la vida social. Sin embargo, dicha división del mundo social es realizada y reforzada desde el punto de vista de la identidad, y por lo tanto de la normativa. Ya que clasificar implica por un lado, jerarquizar y por otro, naturalizar como legítimas ciertas identidades (incluyendo cuerpos, formas de vestir y actuar) en detrimento de otras que son desplazadas a las zonas de la alteridad. Al normatizar una identidad se le brinda a la misma los atributos positivos que la ubican en el lugar de la "normalidad", y la establece como punto de referencia central para ubicar otras posiciones de sujeto. Desde esta postura, se asume que discutir el problema de la identidad y de la diferencia, entendidas éstas como relaciones de poder, requiere poner en cuestión los esquemas binarios mediante los cuáles se organizan ${ }^{7}$.

A modo de ejemplo, en los últimos años, la proliferación en la escena pública y mediática de identidades que se proclaman no heterosexuales y que expresan otras concepciones y experiencias sobre la corporalidad, como la comunidad transgenérica ${ }^{8}$, da cuenta de la artificialidad y la crisis del paradigma heteronorma- 
tivo. No obstante, luchar contra la discriminación y la violencia social sigue siendo el principal objetivo de dichos colectivos relegados a los márgenes simbólicos y materiales de la sociedad.

\section{Consideraciones finales}

Hasta aquí he intentado argumentar que las subversiones de los patrones hegemónicos de los modos de vestir, ponen en primera plana el cuestionamiento de la construcción histórica y social de las identidades de género y/o sexuales binarias. El trabajo ha abordado sociológica e históricamente algunos aspectos teóricos referidos al papel histórico que ha tenido y tiene aún el uso de indumentaria en el proceso de naturalización de las identidades de género binarias en la cultura occidental.

Para ello, el género fue conceptualizado como una tecnología, es decir como un dispositivo propio de la modernidad que determina los "modos de ver", clasificar y enunciar tanto a los cuerpos como a las identidades sociales. Se ha planteado a la indumentaria como un signo pues dichos cuerpos casi nunca se encuentran desnudos, sino que usualmente aparecen regulados en la escena social como cuerpos vestidos y además, dotados de un género.

Por lo tanto, se concluye que la moda y los cambios cíclicos en los modos de vestir no actúan solamente como fenómenos estéticos y de consumo, sino que además, enmascaran las luchas políticas por las construcciones de sentido en torno a los valores sociales de los cuerpos, las sexualidades y los géneros que suponen un devenir identitario.

Desde luego, plantear los modos de vestir desde una dimensión discursiva, ha implicado asumir la relevancia de los usos del lenguaje como práctica significante y generadora de efectos de sentido. Ésta práctica significante (o sea, el lenguaje) es además, el lugar donde se reifican y esencializan los significados culturales y normativos en torno a las identidades de sexo y/o género, los cuerpos y los modos de vestir. Por lo tanto, se requiere un análisis agudo que permita poner en cuestión la creación histórica de estereotipos identitarios sobre lo femenino y / o masculino. Posibilitando la problematización de la producción de los cuerpos generizados como acto sociosemiótico, y a la vez, político. 


\section{Notas}

1 Socióloga (UBA) y doctoranda en Ciencias Sociales en la Universidad de Buenos Aires (UBA) con una beca CONICET. Dicta clases como profesora adjunta en la materia "Sociología" de la carrera de Diseño de Indumentaria y Textil en la Facultad de Arquitectura, Diseño y Urbanismo (FADUUBA).

2 Para un análisis detallado sobre los orígenes de la Sociología se puede consultar: Portantiero, Juan Carlos (1977) La sociología clásica: Durkheim y Weber. Centro Editor de América Latina: Buenos Aires.

3 La homosexualidad como categoría ha surgido en el siglo XIX desde los discursos de la psiquiatría para explicar las conductas sexuales clasificadas como desviadas, tomando de referencia a la matriz heterosexual como la normativa hegemónica (Foucault, 2003 [1977]).

4 Lamas (1995) sostiene que la matriz hetero-normativa determina las identidades de género a partir de la naturalización de la correspondencia "coherente" entre el sexo y el género. Implica la regulación de las prácticas desde una norma que da inteligibilidad a los cuerpos. Jerarquiza como legítima a la identidad heterosexual y otorga el lugar de la alteridad / otredad a las identidades que no cumplen con dicha norma. Teorías feministas más recientes sostienen que el género es producido a partir de la repetición de las prácticas. Es decir, que el género radica en performances que devienen en un constante hacer. Es un proceso abierto a la contingencia que no clausura y por lo tanto, nunca termina (Butler, 1999; De Lauretis, 1996).

5 Relatos acerca del mundo medieval (Bajtin, 1987) datan acerca de un cuerpo construido en torno a los imaginarios religiosos. El cuerpo tradicional respondía a una cosmovisión que no necesitaba de un cuerpo individual, sino de un cuerpo basado en la integración de los lazos sociales a partir del equilibrio entre la Naturaleza y la comunidad.

6 La perspectiva fenomenológica e interaccionista de Goffman, propone pensar al cuerpo privilegiando al orden simbólico y al lenguaje corporal como potencial discurso para analizar la microsociedad (Martinez Barreiro, 2004).

7 Por ejemplo, en el campo de los Estudios de Género y del Feminismo, los principales binarismos identitarios que han sido problematizados refieren a las oposiciones entre: femenino/masculino, heterosexual/homosexual, hombre/mujer, etc. Así, bajo la línea de la corriente post-estructuralista dichos campos de saber han logrado develar que, tanto la definición de los géneros como la oposición entre los sexos, son construcciones sociales. Este enfoque, además, complejiza muchas de las conceptualizaciones feministas históricas, en la medida en que formula una operación de-constructiva que se basa en la re-conceptualización del sexo, trascendiendo la filiación entre sexo y roles sociales.

8 El concepto transgénero proviene de la Teoría Queer, y hace referencia a aquellas identidades que ocupan posiciones más allá del esquema binario, como por ejemplo travestis, transexuales, intersexuales, etc. 


\section{Bibliografía}

Arfuch, Leonor (comp.). Identidades, sujetos y subjetividades. Buenos Aires: Prometeo, 2002.

Arfuch, Leonor y Devalle, Verónica (comp.). Visualidades sin fin. Imagen y diseño en la sociedad global. Buenos Aires: Prometeo, 2009.

Bajtin, Michel. La cultura popular en la Edad Media y en el Renacimiento. El contexto de Francois Rabelais. Madrid: Alianza, 1987.

Badinter, Elizabeth. Um é Outro: relacoes entre homens e mulheres. Rio de Janeiro: Nova Fronterira, 1986.

Becker, Howard. Los extraños. Sociología de la desviación. Buenos Aires: Tiempo Contemporáneo, 1971.

Bourdieu, Pierre. La distinción. Madrid: Taurus, 1998.

Butler, Judith. El género en disputa. México: Paidós, 1999.

De Lauretis, Teresa. Tecnología del género. Mora. 2, 1996.

Deleuze, Pilles. Postdata sobre las sociedades de control en Conversaciones (1972-1990) en www.philosophia.cl / Escuela de filosofía, Universidad ARCIS, 1990.

de Beauvoir, Simone. El segundo sexo. Madrid: Cátedra, 2000, [1949].

Dutra e Mello, José Luiz. Onde vocé comprou esta roupa tem para homem?: A construcao de masculinidades nos mercados alternativos de moda. Rio de Janeiro: Record, 2007.

Elías, Norbert. El proceso de la civilización. México: Fondo de Cultura Económica, 1977.

Entwistle, Joanne. El cuerpo y la moda. Una visión sociológica. Barcelona: Paidós, 2002.

Foucault, Michel. Vigilar y Castigar. Buenos Aires: Siglo XXI Editores, 1989.

----. Tecnologías del yo. Barcelona: Paidós, 1990.

----. Historia de la sexualidad. La voluntad del saber. Buenos Aires: Siglo XXI Editores, 2003, [1977].

Fry, Peter. Da hierarquia a igualdade: a construcao historica homossexualidade no Brasil. Rio de Janeiro: Zahar, 1982.

Goffman, Irving. Estigma. La identidad deteriorada. Madrid: Amorrortu, 2003, [1963].

-----. La presentación de la persona en la vida cotidiana. Madrid: Amorrortu, 2004, [1959].

Gugliermi, Nilda. Disciplinare il lusso: La legislazione suntuaria in italia e in europa tra medioevo ed Etá Moderna. Temas Medievales. Enero/Dic. Vol. $12,2004$.

Hall, Stuart. Who needs identity?. En S. Hall \& P. Du Gay (eds.). Questions of cultural identity. London: Sage, 1996.

Laver, James. Breve historia del traje y la moda. Madrid: Cátedra, 1989.

Laqueur, Thomas. La construcción del sexo. Cuerpo y género desde los griegos hasta Freud. Madrid: Ediciones cátedra, 1984.

Le Breton, David. Antropología del cuerpo y la modernidad. Buenos Aires: Nueva Visión, 1995.

Lipovetsky, Pilles. El imperio de lo efímero. Barcelona: Anagrama, 1994.

Lurie, Allison. El lenguaje de la moda. Barcelona: Paidós, 1994.

Martínez Barreiro, Ana. La moda en las sociedades modernas. Madrid: Tecnos, 1998. 
-----. La construcción social del cuerpo en las sociedades contemporáneas. Papers 73, 2004.

Mauss, Marcel. Las técnicas corporales. París: Puf, 1950.

Morin, Edgar. El espíritu del tiempo. Madrid: Taurus, 1962.

Penhos, Marta. Ver, conocer, dominar. Imágenes de Sudamérica a fines del Siglo XVIII, Argentina: Siglo XXI Editores, 2005.

Portantiero, Juan Carlos. La sociología clásica: Durkheim y Weber. Buenos Aires: Centro Editor de América Latina, 1977.

Riviere, Margarita. Moda: ¿comunicación o incomunicación? Barcelona: Gili, 1977.

Saulquin, Susana. La moda en la Argentina. Buenos Aires: Emecé, 1990.

----. La moda, después. Buenos Aires: ISM, 1999.

Sabsay, Leticia. "Por los rumbos de la economía visual: identidades, cuerpos y estéticas". En: Visualidades sin fin. Imagen y diseño en la sociedad global. Buenos Aires: Prometeo, 2009.

Simmel, Georg. Cultura femenina y otros ensayos. Buenos Aires: Espasa Calpe, 1938.

Sousa Congosto, Francisco de. Introducción a la historia de la indumentaria en España. Madrid: ISTMO, 2007.

Spencer, Herbert. Principios de Sociología. Buenos Aires: Revista de Occidente, 1947.

Turner, Brian. El cuerpo y la sociedad: exploraciones en teoría social. México: FCE, 1989.

Veblen, Thoestein. Teoría de la clase ociosa. México: FCE, 1974.

Vigarello, Georges. Historia de la belleza. El cuerpo y el arte de embellecer desde el Renacimiento hasta nuestros días. Buenos Aires: Nueva Visión, 2005.

Zambrini, Laura. “Cuerpos, indumentarias y expresiones de género: el caso de las travestis de la Ciudad de Buenos Aires". En: Todo sexo es politico. Estudios sobre sexualidades en Argentina Pecheny, Mario; Figari, Carlos y Jones, Daniel (comp.) Buenos Aires: Libros del Zorzal, 2008.

-----. "Prácticas del vestir y cambio social. La moda como discurso" en Revista Questions Nro. 23 ISSN 1669-6581. Buenos Aires: Facultad de Periodismo y Comunicación Social de la Universidad de La Plata 2009.

Zambrini, Laura \& Paula Iadevito. “Feminismo Filosófico y Pensamiento Postestructuralista: Teorías y Reflexiones acerca de las nociones de sujeto e identidad femenina" en Sexualidad, Salud y Sociedad. Revista Latinoamerica$n a$, Nro. 2. ISSN 1984-6487. Rio de Janeiro, Brasil: Universidad Estadual de Rio de Janeiro (UERJ), 2009. 